LINGUA, Vol. 15, No. 2, September 2018

p ISSN: 1979 9411; e ISSN: 2442 238X

Http://lingua.pusatbahasa.or.id; Email: presslingua@gmail.com

Center of Language and Culture Studies, Surakarta, Indonesia

Juanda \& Azis. 2018. Penyingkapan Citra Perempuan Cerpen Media Indonesia: Kajian Feminisme.

Lingua (2018), 15(2):71 82. DOI: 10.30957/lingua.v15i2.478.

\title{
PENYINGKAPAN CITRA PEREMPUAN \\ CERPEN MEDIA INDONESIA: KAJIAN FEMINISME
}

\author{
Juanda $^{1}$ \& Azis ${ }^{2}$ \\ Fakultas Bahasa dan Sastra, Universitas Negeri Makassar \\ Jalan Daeng Tataraya, Kampus Parangtambung \\ Malengkeri, Makasar, Indonesia \\ E-mail: ${ }^{1}$ juanda@unm.ac.id \& 2 azis@unm.ac.id.
}

\begin{abstract}
One of the female phenomena which were authored by the author's short stories in Media Indonesia is the narrative of oppressed women. The purpose of this study is to explore the image of women in short stories in the Media Indonesia. This type of research is descriptive qualitative research that focuses on the image of women. The approach used in this research is the feminism approach. The data were analysis techniques using heuristic and hermeneutic techniques. The results of the study indicate that there are various negative treatments experienced by women. The author used the short stories as a representation of their images through the Media Indonesia daily. Women's image is manifested in the form of a physical image, psychic, helpless, resigned to the situation, housewife, loyalty, child guard, domestic, husband's companion, and social.
\end{abstract}

Keywords: women's image, short story, and feminism

DOI: 10.30957/lingua.v15i2.478.

\section{PENDAHULUAN}

Karya sastra sebagai bentuk bahasa yang banyak merefleksikan kehidupan dan realitas manusia.Dalam ilmu sastra, feminisme merupakan konsep kritik yang fokus analisisnyamengenai persoalan perempuan. Altman (2003) mengemukakan pada era 1970-an, para penulis perempuan lebih cenderung bersikap pesimis dan skeptis dalam menuliskan cerita. Santosa (2009:47-56) pengkritik dan pembaca laki-laki belum mampu menafsirkan dan menilai secara akurattulisan pengarang perempuan.Sugihastuti (2002:18) menegaskan feminisme sebagai gerakan persamaan antara laki-laki dan perempuan di segala bidang baik politik, ekonomi, pendidikan, sosial maupun kegiatan terorganisasi yang mempertahankan hak-hak serta kepentingan perempuan. Selanjutnya Sugihastuti mengatakan penindasan dan pemerasan kepada kaum perempuan dalam masyarakat terjadi di tempat kerja dan rumah tangga. Zakariya (2017:230) diskriminasi gender di seluruh dunia dicirikan oleh kebijakan negara, keterlibatan institusional, kebungkaman budaya, dan eksploitasi lingkungan. 
LINGUA, Vol. 15, No. 2, September 2018

p ISSN: 1979 9411; e ISSN: 2442 238X

Http://lingua.pusatbahasa.or.id; Email: presslingua@gmail.com

Center of Language and Culture Studies, Surakarta, Indonesia

Juanda \& Azis. 2018. Penyingkapan Citra Perempuan Cerpen Media Indonesia: Kajian Feminisme. Lingua (2018), 15(2):71 82. DOI: 10.30957/lingua.v15i2.478.

Madsen (2000:35-37) feminisme merupakan ideologi serta paham mengenai persamaan hak antara pria danperempuan. Feminisme berasal dari bahasa Latin, kata "femina" berarti memiliki karakter keperempuanan. Rose (1990) menjelaskan bahwa gerakan feminis sebagai usaha meningkatkan kedudukan serta derajat kaum perempuansupaya sejajar atau sama dengan laki-laki. Pada akhirnya, perempuan dapat menunjukkan tokoh-tokoh citra perempuan yang kuat dan mendukung nilai-nilai feminisme. Youssef (2017) kondisi mesir dalam buku Nawal El-Saadawi menguraikan pemarginalan kaum perempuan, eksploitasi kelas bawah oleh kelas atas, dan kontrol agama di arena publik-politik. Dia dianggap unik, karena tidak ada tulisan tentang seorang perempuan Arab sebab dianggap tabu

Gambaran perempuan yang mengikuti kodratnya dipersepsi sebagai tradisional. Sifat gender perempuan yang lemah lembut, halus penuh perasaan, emosional, membawa pemahaman bahwa perempuan tidak layak menjadi seorang pemimpin karena dikhawatirkan tidak bisa membuat keputusan (Ma'shimah, 2012). Dilema mental dan emosional seorang wanita yang memiliki suami lima orang dengan alas dan untuk berdarma (Thakar, 2011:7). Feminisme memberikan perhatian pada jenis kelamin sebagai suatu prinsip pengatur kehidupan sosial yang secara menyeluruh oleh relasi kekuasaan yang menyubordinasikan perempuan di bawah laki-laki (Barker, 2000:177). Gerakan feminis muncul akibat tumpang tindihnya makna yang tidak dipahami secara baik oleh masyarakat, antara gender dan jenis kelamin (Darusalam, 2016:221-223). Banyak penulis dari kalawangan wanita India yang memperjuangkan kaum perempuan dalam masyarakat yang selalu didominasi oleh laki-laki (Rajeswari, 2018:9).

Citraan sebagai gambaran yang dimiliki seseorang mengenai pribadi, kesan mental visual sebagai makna sebuah kata, frasa atau kalimat, dan merupakan unsur dasar konsep citra perempuan(Sugihastuti dan Suharto, 2000:45). Citra perempuan dibedakan menjadi dua,yaitu citra diri perempuan dan citra sosial perempuan. Citra diri perempuan merupakan dunia yang typis, yang khas dengan segala macam tingkah lakunya. Citra diri perempuan merupakan keadaan dan pandangan perempuan yang berasal dari dalam dirinya sendiri, yang meliputi aspek fisik dan aspek psikis (Sugihastuti dan Suharto, 2000:112-113).

Citra sosial perempuan merupakan citra perempuan yang erat hubungannya dengan norma dan sistem nilai yang berlaku dalam satu kelompok masyarakat, tempat perempuan sebagai bagian dan berhasrat mengadakan hubungan antarmanusia (Martha, 2010). Kelompok masyarakat itu adalah kelompok keluarga dan kelompok masyarakat luas. Dalam keluarga, perempuan berperan sebagai istri, ibu, dan sebagai anggota keluarga yang setiap peran saling berkaitan serta mendatangkan konsekuensi sikap sosial. Citra sosial perempuan merupakan masalah pengalaman diri, seperti dicitrakan dalam citra diri perempuan dan citra sosialnya. Pengalaman-pengalaman inilah yang menentukan interaksi sosial perempuan dalam masyarakat sehingga perempuan bersikap, termasuk sikapnya terhadap laki-laki. Hal penting yang mengawali citra sosial perempuan adalah citra dirinya (Sugihastusi dan Suharto, 2000:143-144).

Citra perempuan dalam aspek keluarga, perempuan berperan sebagai isteri, ibu, dan anggota keluarga masing-masing.Peran perempuan mendatangkan konsekuensi sikap sosial, yang satu dengan lainnya berkaitan. Sebagai isteri seorang perempuan 
LINGUA, Vol. 15, No. 2, September 2018

p ISSN: 1979 9411; e ISSN: 2442 238X

Http://lingua.pusatbahasa.or.id; Email: presslingua@gmail.com

Center of Language and Culture Studies, Surakarta, Indonesia

Juanda \& Azis. 2018. Penyingkapan Citra Perempuan Cerpen Media Indonesia: Kajian Feminisme.

Lingua (2018), 15(2):71 82. DOI: 10.30957/lingua.v15i2.478.

mencintai suami, memberikan motivasi, dan mendampingi. Perempuan dalam karya sastra ditampilkan dalam kerangka hubungan ekuivalensi dengan seperangkat tata nilai marginal, tersubordinasi, stereotip, sentimentalitas, perasaan, dan spritualitas (Hayati, 2012). Bagi suku Jawa istri lebih banyak berperan pada pengasuhan anak dan masalah keuangan dalam rumah tangga (Putri, Dyah P.K., dan Sri Lestari, 2015:72).

Cerpen di Indonesia beragam jenisnya, mulai dari yang berisi cerita lucu, cerita remaja, cerita dewasa, hingga cerita horor. Sifat menindas dan membatasi peran yang diberikan kepada perempuan dan tekanan yang ditimpakan kepada mereka untuk memenuhi tugas-tugas penting yang dituduhkan ini, putus asa, melarikan diri dari kehidupan ini dan mengembangkan identitas baru merupakan kisah yang banyak ditulis oleh para penulis perempuan Arab (Quawas, 2014:63). Cerpen pada saat ini cukup popular dibandingkan karya sastra lainnya karena penyampaiannya yang cukup mudah dijumpai seperti pada media cetak maupun media elektronik. Dengan kacamata daya tarik neoliberal, aspirasi pedagogis kritis cerita dapat dengan mudah menyebar di bawah kontrol logika kapitalisme (Yin, 2017:73). Sebaliknya (Vardani, 2018:23) menekankan aspek Islamiah pada cerpen dalam penelitiannya terhadap cerpen Aku Ingin Emak Masuk Surga karya Maiyade Laila Yane menunjukkan penanaman nilai-nilai karakter Islam menurut Borba, antara lain nilai empati, hati nurani dan kontrol diri. Penelitian Puboarsi, Kundharu S., dan Suyitno S. (2017:195) menganalisis karakter Preman, sebuah antologi cerita pendek yang ditulis oleh penulis Jawa implikasinya untuk mengajar bahasa Jawa bagi siswa sekolah menengah. Analisis berfokus pada karakterisasi, tema dan judul cerita pendek yang berkaitan. Tema yang digunakan dalam cerkak ini adalah tema mengenai problem-problem sosial yang terdapat pada masuyarakat khususnya masyarakat pedesaan.

Media Indonesia adalah salah satu koran atau media yang sering memuat cerpen yang menceritakan kisah perempuan. Cerpen ini menarik dikaji dari sudut pandang feminisme. Pemilihan kata yang digunakan sangat variatif dan tema yang disajikan memunculkan kisah-kisah para perempuan. Penceritaan yang merupakan replika imaji pengarang dari dunia nyata. Selain itu, menampilkan nilai-nilai budaya yang perlu diperhatikan dan diajarkan kepada generasi bangsa Indonesia. Kebudayaan diwariskan dari generasi ke generasi dengan cara belajar (Juanda, 2010:2).

Penelitian feminisme telah dilakukan oleh berbagai ahli antara lain, Solihah (2013) "Problematika Perempuan: Presentasi Kekerasan Gender pada Cerpen "Lintah" dan "Menyusu Ayah" Karya Djenar Maesa Ayu (Problematics of Women: Presentation of Gender Violence on the Short Story "Lintah" and"Menyusu Ayah" by Djenar Maesa Ayu)". Selanjutnya, Quawas (2014) "Pinched Lives and Stolen Dreams in Arab Feminist Short Stories", Priyatna (2018) "Feminist Voice in the Works of Indonesian Early Woman Writers: Reading Novels and Short Stories by Suwarsih Djojopuspito", Negari (2015) "Perempuan Dan Ritual Guru Piduka dalam Cerpen "Surat dari Puri" Karya Widiasa Keniten", Saptawuryandari (2016) "Perempuan yang Termarginalkan dalam Cerpen "Menuju Kamar Durhaka" dan "Berita dari Parlemen" Karya Utuy Tatang Sontani", Khifdiyatun Nafiyah dan Hari Bakti (2016) "Permasalahan Perempuan dalam Kumpulan Cerpen Sepasang Lampion karya Triyanto Triwikromo", Resky. 
LINGUA, Vol. 15, No. 2, September 2018

p ISSN: 1979 9411; e ISSN: 2442 238X

Http://lingua.pusatbahasa.or.id; Email: presslingua@gmail.com

Center of Language and Culture Studies, Surakarta, Indonesia

Juanda \& Azis. 2018. Penyingkapan Citra Perempuan Cerpen Media Indonesia: Kajian Feminisme.

Lingua (2018), 15(2):71 82. DOI: 10.30957/lingua.v15i2.478.

Penelitian di atas, semuanya telah mengkaji feminisme dari perspektif yang berbeda-beda. Namun, penelitian tersebut belum mendalam pada citra perempuan dalam cerpen Media Indonesia. Oleh karena itu, pada penelitian ini peneliti memfokuskan kajiannya pada citra perempuan dalam cerpen yang diterbitkan Media Indonesia.

\section{METODE}

Penelitian ini adalah jenis penelitian kualitatif deskriptif. Data yang digunakan pada penelitian ini, yakni cerpen yang terdapat pada Harian Media Indonesia. Sumber data berasal dari lima cerpen, yaitu yang berjudul "Jemini dan Tuana Busu Klarten" yang ditulis oleh Teguh Affandi pada 07 Mei 2017, "Tahi Lalat" yang ditulis oleh M. Shoim Anwar pada 19 Feb 2017. "Mata yang Menyiksa" yang ditulis oleh Ganda Pakasih, 1 Oktober 2017; "Lumpur Api (Begenggek)" yang ditulis oleh Catur Pelita pada 29 April 2018, "Sangkar Perkawinan" yang ditulis oleh Muna Masyari pada 04 Maret 2018. Teknik pengumpulan data dalam penelitian ini adalah studi dokumentasi pustaka. Data dianalisis dengan pembacaan kritis dan pemaknaan secara tematik melalui analisis isi (Miles \& Hubermen, 1994). Analisis data dilakukan dengan langkah-langkah sebagai berikut: (1) Reduksi data, (2) Penyajian data, (3) Pengambilan simpulan dan verifikasi (Miles \& Hubermen, 1994).

\section{HASIL DAN BAHASAN}

Citra perempuan dalam cerpen Media Indonesia terdiri atas berbagai jenis. Hal ini berdasarkan latar belakang para pengarang yang dalam mencitrakan kaum perempuan melalui karya sastra yang dibuatnya melalui cerpen. Media Indonesia hanya memuat gendre sastra cerpen rutin mingguan di antara genre sastra yang lain seperti film, drama, dan puisi. Citra perempuan berkaitan dengan keluarga dan sosial. Citra keluarga berkaitan dengan peran perempuan sebagai pengasuh anak pengurus suami. Citra sosial berkaitan dengan perempuan sebagai pendamping suami dalam berkehidupan masyarakat. Citra perempuan tersebut dapat dilihat dalam bentuk tabel 1 .

Tabel 1. Citra Perempuan Cerpen Harian Media Indonesia

\begin{tabular}{|c|c|c|c|}
\hline No. & Pengarang & Judul Cerpen & Citra Perempuan \\
\hline 1. & Catur Pelita & LA & $\begin{array}{c}\text { Fisik, dandan, Cantik,tak berdaya, } \\
\text { pasrah, pekerja malam }\end{array}$ \\
\hline 2. & Ganda Pakasih & MYM & $\begin{array}{c}\text { Psikis, cantik, tak berdaya, fisik, } \\
\text { keluarga }\end{array}$ \\
\hline 3. & M. Shoim Anwar & TL & Lemah, keluarga \\
\hline 4. & Teguh Affandi & JTBK & $\begin{array}{c}\text { Keluarga: penjaga anak, ibu rumah } \\
\text { tangga, domestic }\end{array}$ \\
\hline 5. & Muna Masyari & SK & $\begin{array}{c}\text { Sosial, Pendamping suami, } \\
\text { kesetiaan }\end{array}$ \\
\hline
\end{tabular}

\section{Lumpur Api (LA)}

Dalam cerpen ini pembaca disuguhkan citra fisik tokoh perempuan yang digambarkan dalam cerpen tersebut. Cerpen ini oleh pengarang mendeskripsikan 
kehidupan tokoh perempuan yang bekerja sepanjang malam untuk menghidupi keluarganya. Hal tersebut terlihat jelas dalam kutipan berikut:

"Akhirnya yang ditunggu melenggang dari kamar, bak penari yang hendak pentas ke panggung. Usia perempuan itu menjelang 30 tahun, tubuhnya masih segar, wajahnya cantik, walau dandanannya agak menor (Pelita, 2018).”

Kutipan di atas menjelaskan bahwa penulis melakukan kritik terhadap standarstandar yang telah dilekatkan pada masyarakat tentang perempuan. Rose (1990) menjelaskan bahwa gerakan feminis sebagai usaha meningkatkan kedudukan serta derajat kaum perempuan supaya sejajar atau sama dengan laki-laki. Citra perempuan dalam keluarga juga jelas digambarkan dalam cerpen tersebut. Hal ini jelas terlihat dalam kutipan berikut:

"Si lesung pipit turun, mengecup pipi suami seraya mendulang pesan, "Sudah, Mas pulanglah, jangan bepergjan, jagain anak kita! (Pelita, 2018)."

Kutipan tersebut menggambarkan sosok perempuan sebagai seorang istri yang mengharapkan suaminya segera pulang dan tidak lagi bepergian. Kutipan tersebut mengisyaratkan bagaimana penulis menggambarkan sosok istri yang kerap kali ditinggal pergi oleh sang suami dan sangat jarang bersama anak dan istrinya. Banyak penulis dari kalangan wanita memperjuangkan kaum perempuan dalam masyarakat yang selalu didominasi oleh laki-laki (Rajeswari, 2018:9).

Selain citra fisik dan citra prempuan sebagai seorang istri dalam keluarga yang digambarkan penulis, terdapat pula citra psikis seperti dalam kutipan berikut:

"Di mana kakek? Tiwi ingin ketemu yah"

"Kakek meninggal di kota bencana tanah longsor menimpa desa."

"Nenek?'

"Juga iya. Semua saudara Ayah jadi korban. Hanya Ayah yang selamat."

"Kasihan, Tiwi tak punya kakek-nenek, Yah. Ibu tak pernah certain kakek nenek, dan..."

"Sudahlah sayang, yang penting Tiwi masih punya ayah dan ibu yang sayang pada Tiwi."

Kabut di wajah bocah imut mengabur." Ya. Ayah, apakah Ibu sudah makan?"...(Pelita, 2018)."

Kutipan di atas menunjukkan bagaimana psikis seorang Tiwi yang ditinggal pergi oleh sang Kakek dan Nenek hingga membuatnya tidak pernah melihat apalagi merasakan bagaimana kasih sayang kakek dan nenek pada cucu perempuannya. Kesedihan gadis kecil itu sangat jelas tergambar dalam kutipan tersebut. Katoria (2011) menjelaskan, tentang perempuan dan seksualitas. Meskipun ia telah didefinisikan sebagai karakter penurut oleh Ismat Chugtai, ia sama sekali tidak lembut berbicara seperti perempuan pada masa itu. Dia sangat menyadari hasrat seksualnya dan dia tidak 
LINGUA, Vol. 15, No. 2, September 2018

p ISSN: 1979 9411; e ISSN: 2442 238X

Http://lingua.pusatbahasa.or.id; Email: presslingua@gmail.com

Center of Language and Culture Studies, Surakarta, Indonesia

Juanda \& Azis. 2018. Penyingkapan Citra Perempuan Cerpen Media Indonesia: Kajian Feminisme. Lingua (2018), 15(2):71 82. DOI: 10.30957/lingua.v15i2.478.

menyembunyikannya, dia cukup berani bermain-main dengan pria. Dia jujur tentang kebutuhan fisiknya dan menganggapnya sebagai kebutuhan dasar manusia yang harus dipenuhi.

Citra perempuan yang tak berdaya sebagai seorang istri, sebagai WTS, sekaligus ibu dari seorang gadis perempuan terlihat dalam kutipan berikut:

"Sungguh, ia pernah juga jenuh dengan pekerjaannya. Sendainya ada peluang, mungkin ia akan berhenti. Tapi setidaknya bukan hari ini. Ia masih ingin memiliki rumah, uang banyak untuk sekolah Tiwi, makan. Untuk modal kerja setelah peyot (Pelita, 2018)".

Dari beberapa kutipan di atas disimpulkan bahwa cepen tersebut menggambarkan sosok perempuan yang tidak berdaya dan pasrah terhadap keadaan yang dijalaninya saat ini demi keberlangsungan hidupnya dan juga keluarganya. Youssef (2017) menguraikan pemarginalan kaum perempuan, eksploitasi kelas bawah oleh kelas atas, dan kontrol agama di arena publik-politik. Si Tokoh perempuan yang bernama Si Lesung Pipit pasrah pada keadaan sosial yang mengharuskan bekerja sepanjang malam demi menghidupi keluarganya. Di sini perempuan dicitrakan sebagai pencari nafkah, pekerja malam, pedandan sedangkan suaminya tidak berusaha mencari pekerjaan. Jadi, dalam cerpen ini terjadi eksploitasi bagi kaum wanita.

\section{Mata yang Menyiksa (MYM)}

Melalui peristiwa yang diungkap (Saptawuryandari, 2016:45) dalam cerpen "Menuju Kamar Durhaka" terungkap dan tergambar ada dua tokoh yang bertolak belakang. Tokoh Aku adalah perempuan sederhana dan tradisional pada sistem pembagian kasta di Bali yang hierarkhis dan patriarkis berdampak negatif terhadap kaum perempuan (Windiyarti, 2008:293). Berbeda halnya dalam cerpen yang berjudul Mata yang Menyiksa menyuguhkan pembaca pada awal cerita yang terkait dengan psikis tokoh yang ada dalam cerita tersebut. Perempuan rela menghilangkan penglihatannya, membutakan dirinya karena perselingkuhan si laki-laki di depan matanya. Hal ini digambarkan dalam kutipan berikut:

"Sudah beberapa minggu perempuan bermata sedih itu tinggal di rumah pengembaraan, di sebuah kota di mana kabut lebih sering muncul. Apa yang disedihkan perempuan itu adalah kesedihan tentang seorang lelaki yang wajahnya berlumuran darah karena membutakan matanya sendiri (Pekasih, 2017).”

Citra psikis sangat jelas digambarkan pada kutipan di atas, yang menggambarkan bagaimana sosok perempuan yang sangat sedih melihat penderitan lelaki yang membutakan matanya sendiri. Kutipan cerpen tersebut juga menggambarkan betapa tersiksanya perempuan itu menyaksikan lelaki itu berlumuran darah karena telah membutakan matanya sendiri.

Citra psikis juga digambarkan dalam kutipan cerpen pada bagian lain cerita. Citra psikis tersebut digambarkan pada kutipan berikut: 
“Terimakasih." Mayan menghirup serumpun Rose mekar dalam-dalam. Butakanlah mataku dengan tangkai-tangkai mawar ini Ranu biar kita menjadi sepasang kekasih buta. Aku lama mencarimu. Aku menderita sejak melihat darah itu, aku sungguh menyesali semua itu (Pekasih, 2017)."

Citra psikis begitu terlihat pada kutipan tersebut yang menggambarkan sosok perempuan yang begitu menyesali perbuatannya kepada kekasihnya hingga ingin mengikuti kekasihnya untuk membutakan kedua matanya membayar apa yang pernah kekasihnya juga lakukan untuk membutakan matanya karena melihat perselingkuhan perempuan itu dengan lelaki lain. Selain citra psikis, ditemukan juga citra fisik yang digambarkan dalam kutipan berikut:

"Dia istriku, namanya Loyansari, kami sudah kenal lama di daerah ini, dia membutakan matanya sendiri karena melihat perselingkuhan suaminyalalu dia datang menemuiku dan kami saling membutuhkan, mencintai dalam kebutaan, seiring waktu kami merasa tidak buta, cinta kami bercahaya (Pekasih, 2017)."

Kutipan di atas menggambarkan citra fisik seorang perempuan buta yang menikah dengan lelaki buta. Perempuan secara fisik membutakan matanya karena melihat suaminya selingkuh. Secara psikis perempuan tersebut mengalami penderitaan batin akibat perlakuan dari suaminya yang selingkuh.

Citra keluarga juga digambarkan penulis dalam cerpennya, penulis menggambarkan betapa sosok perempuan yang menjadi istri dalam cerpen tersebut tidak ingin kehilangan kekasihnya lagi. Pernyataan tersebut digambarkan dalam kutipan berikut:

"Limbo dan istrinya melewati jalan ke arah matahari jatuh, bergandengan tangan, istrinya itu pasti tak membiarkan suaminya pergi sendiri, juga tak ingin kekasihnya dari masa lalu datang lagi mendekat membawa penyesalan, ujung tongkatnya ia sambarkan ke sana ke mari (Pekasih, 2017)."

\section{Tahi Lalat (TL)}

Kesetaraan yang diinginkan kaum perempuan antara lain: Pendidikan, beban kerja dan kehidupan sosial (Wardani dan Yunia P.A., 2016:12). Citra masyarakat yang digambarkan dalam kutipan berikut:

"Jujur kukatakan, Pak Lurah juga sering menggunakan cara-cara kotor. Selama menjabat, tidak sedikit warga yang kehilangan sawah ladang dan berganti dengan perumahan mewah. Warga yang tinggal di tempat strategis, melalui perangkat desa Pak Bayan, dirayu agar menjual tanahnya dengan harga yang lumayan mahal. Begitu tanah-tanah yang strategis itu terlepas dari pemilikinya, Pak Lurah semakin gencar membujuk yang lain dengan cara memanggilnya ke kantor kelurahan (Anwar, 2017)." 
LINGUA, Vol. 15, No. 2, September 2018

p ISSN: 1979 9411; e ISSN: 2442 238X

Http://lingua.pusatbahasa.or.id; Email: presslingua@gmail.com

Center of Language and Culture Studies, Surakarta, Indonesia

Juanda \& Azis. 2018. Penyingkapan Citra Perempuan Cerpen Media Indonesia: Kajian Feminisme. Lingua (2018), 15(2):71 82. DOI: 10.30957/lingua.v15i2.478.

Kutipan di atas menggambarkan sosok Pak Lurah sebagai tokoh masyarakat yang curang di mata masyarakat. Citra perempuan dalam hal ini istri Pak Lurah di mata masyarakat digambarkan dalam kutipan berikut:

"Ada tahi lalat di dada istri Pak Lurah, itu kabar yang tersebar di tempat kami. Mungkin orang-orang masih sungkan untuk mengatakannya secara terbuka. Mereka menyampaikan kabar itu dengan suara pelan, mendekatkan mulut ke telinga pendengar, sementara yang lain memasang telinga lebih dekat ke mulut orang yang sedang berbicara. Mereka manggut-manggut tersenyum sambil membuat kode gerakan menggelembung di dada dengan dua tangan, lalu menudingkan telunjuk ke dada sendiri sebagai pertanda telah mengerti (Anwar, 2017)."

Kutipan di atas menggambarkan betapa tidak berdayanya seorang istri lurah yang digunjingkan oleh warganya, menjadikan istrinya sebagai bagian dari permainan politik yang sedang dimainkan oleh suaminya. Ada pula citra fisik yang digambarkan pengarang dalam cerpen tersebut. Berikut ini kutipan yang menggambarkan citra fisik dalam cerpen Tahi Lalat:

"Lo, Bu Lurah yang sekarang masih perawan, berparas cantik. Selisih umurnya katanya dua puluh tahun."

... Semakin mendekati masa pendaftaran calon lurah, berita adanya tahi lalat di dada istri Pak Lurah semakin senter. Bumbu-bumbu pembicaraan semakin banyak. Pembicaraan tidak hanya tertumpu pada tahi lalat di dada istri Pak Lurah, tapi meluas hingga sekujur tubuh istri Pak lurah ditelanjangi (Anwar, 2017).”

Kutipan di atas menggambarkan kecantikan dan betapa mudanya sosok perempuan menjadi istri seorang Lurah yang curang itu. Namun, kutipan tersebut menggambarkan betapa tak berdayanya sosok perempuan yang menjadi istri lurah hingga sekujur tubuh yang tidak terlihat pun menjadi pembicaraan warga setempat.

\section{Jemini dan Tuan Busu Klarten(JTBK)}

Pada cerpen Jemini dan Tuan Busu Klarten pengarang mengekspresikan pengalaman batinnya melalui bahasa sehari-hari (Yasin, 2016:196). Dalam cerpen ini ditemukan adanya citra perempuan seperti pada kutipan berikut:

"Jemini memang membantu menyajikan makanan, mencuci, dan mengepel. Tapi Jemini punya peran lebih, yaitu soal mendidik Garcia tentang bagaimana tubuh perempuan berubah sesuai umur (Affandi, 2017).”

Kutipan tersebut menunjukkan adanya citra perempuan dalam keluarga sebagai pengurus anak. Sebagai seorang kepala keluarga, tokoh aku memercayakan urusan dapur kepada pembantu karena ketidakmampuan mengurus anaknya karena ia 
LINGUA, Vol. 15, No. 2, September 2018

p ISSN: 1979 9411; e ISSN: 2442 238X

Http://lingua.pusatbahasa.or.id; Email: presslingua@gmail.com

Center of Language and Culture Studies, Surakarta, Indonesia

Juanda \& Azis. 2018. Penyingkapan Citra Perempuan Cerpen Media Indonesia: Kajian Feminisme.

Lingua (2018), 15(2):71 82. DOI: 10.30957/lingua.v15i2.478.

seorang laki-laki. Di sisi lain Jemini mempunyai suami yang pengangguran. Di dalam cerpen in perempuan dicitrakan sebagai pekerja yang merupakan problem sosial yang terjadi dalam masyarakat. Penelitian yang dilakukan oleh (Puboarsi, Kundharu S., dan Suyitno S., 2017:195) menganalisis karakter Preman, sebuah antologi cerita pendek dengan tema mengenai problem-problem sosial yang terdapat pada masyarakat khususnya masyarakat pedesaan.

\section{Sangkar Perkawinan (SP)}

Pada cerpen SangkarPerkawinan terdapat citra perempuan dalam keluarga sebagai seorang istri yang mendampingi suami seperti pada kutipan berikut:

"Bagi istri, selama tinggal di rumah hantaran, cinta dan kesetiaan harus dipertaruhkan!” ...

"Seorang istri adalah baju bagi suami. Begitu pun sebaliknya!" jelas ibu. "Maksud Ibu?" keningmu mengkerut. "Seorang istri harus menjadi hiasan suami. Jadi pelengkap ketidaksempurnaannya. Penutup celah kekurangannya! (Masyari, 2018)."

Seorang perempuan ketika telah menjadi seorang istri harus mengikuti keinginan sang suami apapun kondisinya. Seorang perempuan harus menjaga kesetiaannya terhadap suaminya. Selain itu, terdapat citra sosial perempuan, seperti pada kutipan berikut:

"Lihatlah, sangat jarang perempuan dibawakan hantaran semahal ini," tambah ibu kembali menyapu sekeliling; ranjang, lemari, kursi, luas rumah, lalu tengadah menyapu usuk-usuk atap dengan takjub (Masyari, 2018)."

Pada kutipan di atas seorang perempuan saat menjadi seorang suami di mata masyarakat adalah mengurus rumah tangga. Selain itu, perempuan selalu menjadi korban kekerasan dalam rumah tangga (KDRT). Tokoh perempuan Jumarti diceraikan oleh suaminya Ujang akibat kesalahpahaman dan masalah sepele yang membuat si suami salah kaprah dan cemburu. Dalam cerpen SP Jumarti di tuduh selingkuh sebab setiap pagi keramas sehingga sang suami yang pulang pagi dari kerja (sopir truk) mencurigai istrinya berbuat serong di balakang sepeninggal sang suami. Padahal si Perempuan keramas akibat anak laki-lakinya yang menjelang umur dua tahun kencingnya selalu menyembur kemana-mana ketika tidur. Istri lebih banyak berperan pada pengasuhan anak dalam rumah tangga (Putri, Dyah P.K. dan Sri Lestari, 2015:72).

\section{SIMPULAN}

Berdasarkan hasil penelitian di atas maka dapat disimpulkan bahwa citra perempuan dalam cerpen harian Media Indonesia, yaitu: Citra Perempuan dalam cerpen Lumpur Api (Begenggek) terdapat citra fisik yaitu perempuan yang digambarkan secara fisik selalu terlihat cantik, citra perempuan dalam keluarga adalah sosok yang kuat, pemberani, dan pahlawan bagi anak dan keluarganya, dan citra perempua secara psikis yang tidak mampu berbuat apa-apa menerima apa yang terjadi pada dirinya; Citra 
LINGUA, Vol. 15, No. 2, September 2018

p ISSN: 1979 9411; e ISSN: 2442 238X

Http://lingua.pusatbahasa.or.id; Email: presslingua@gmail.com

Center of Language and Culture Studies, Surakarta, Indonesia

Juanda \& Azis. 2018. Penyingkapan Citra Perempuan Cerpen Media Indonesia: Kajian Feminisme.

Lingua (2018), 15(2):71 82. DOI: 10.30957/lingua.v15i2.478.

perempuan dalam cerpen Mata yang Menyiksa terdapat citra perempuan secara psikis perempuan yang digambarkan dalam cerpen tersebut adalah perempuan yang tidak berdaya menjalani hidupnya dalam kebutaan, secara fisik digambarkan sosok perempuan yang buta, dan citra perempuan dalam keluarga digambarkan seorang perempuan yang setia pada suami keduanya namun, jadi perempuan penghianat di awalawal cerita; citra perempuan dalam cerpen Tahi Lalat ditemukan citra perempuan dalam masyarakat yang digambarkan oleh seorang perempuan yang melayani lelaki yang berpengaruh pada dirinya, citra perempuan secara fisik digambarkan perempuan yang muda, cantik, dan bertahi lalat; dan citra perempuan dalam keluarga digambarkan seorang perempuan yang rela melakukan apapun demi suaminya meskipun harus dilibatkan sebagai mainan politik; citra perempuan dalam cerpen Jemini dan Tuan Busu Klarten ditemukan citra perempuan dalam aspek keluarga; Citra Perempuan dalam Cerpen Sangkar Perkawinan, yakni citra perempuan yang mencerminkan ranah keluarga dan citra sosial.

\section{DAFTAR PUSTAKA}

Affandi, Teguh.(2017). "Jemini dan Tuan Busu Klarten”. http://mediaindonesia.com. Diunduh 8/5/2018.

Altman, Meryl.(2003). "Beyond Trashiness:The Sexual Language of 1970s Feminist Fiction."Journal of International Women's Studies 4(2), 7-19.

Anwar, Shoim. (2017). Tahi Lalat. http://mediaindonesia.com. Diunduh 8/5/2018.

Barker, C. (2000). Cultural Studies, Teori dan Praktik. Terjemahan oleh Nurhadi. Yogyakarta: KreasiWacana.

Catur, Kartika Pelita. (2018). Lumpur Api (Begenggek). http://mediaindonesia.com. Diunduh 8/5/2018

Darusalam, Zulfardi. (2016). Kajian Feminisme Novel Maimunah "Cinta Sang Perawan" Karya Charisma W.Inovasi Pendidikan, Jurnal IlmiahPendidikan FKIP Universitas Muhammadiyah Sumatera Barat, 2(15), 18-25.

Hayati, Yenni. (2012). "Representasi Ketidakadilan Gender" dalam Cerita dari Blora Karya Pramodya Ananta Toer: Kajian Feminisme.Journal Attavisme, 15(2),163176.

Juanda, Juanda.(2010). "Peranan Pendidikan Formal dalam Proses Pembudayaan." Lentera Pendidikan, Jurnal Ilmu Tarbiyah dan Keguruan, 13(1), 1-15.

Katoria, M. (2011). "Woman and Sexuality: Gender-Class Interface in Selecetd Short of Ismat Chugtai. The criterion: An international journal in the English, 2(4), $1-9$

Madsen, Deborah L. (2000). "Feminist Theory and Literary Practice"..London: Pluto Press.

Martha, Nia Ulfa. (2010). "Citra Istri Dalam Kumpulan Novelet Dunia Tnpa Warna" Karya Mira W (sebuah Kajian Satra Feminis): FKIP Unikal. Journal Muwazah, 2(1), 225-234.

Ma'Simah, Lift Aanis. (2012).“Teks-teks keislaman dalam kajian feminisme muslim”: Telaah metodologis atas pandangan feminis muslim terhadap penciptaan dan kepemimpinan perempuan. Journal SAWWA, 7(2), 67-90. 
Masyari, Muna. (2018). "Sangkar Perkawinan”.http://mediaindonesia.com. Diunduh 8/5/2018.

Miles, Matthew B. and Huberman. (1994). Qualitatif Data Analysis: An Expended Sourcebook $2^{\text {nd }}$ Edition. New York: Sage Publication.

Nafiyah, Khifdiyatun \& Hari Bakti. (2016). "Permasalahan Perempuan" dalam Kumpulan Cerpen Malam Sepasang Lampion Karya Triyanto Triwikromo.Seloka: Jurnal Pendidikan Bahasa dan Sastra Indonesia, 5(1), 21-29.

Negari, Ni Putu Ekatini. (2015).’Perempuan Dan Ritual Guru Piduka" dalam Cerpen "Surat Dari Puri" Karya Widiasa Keniten. Jurnal Aksara. 27, 107-112.

Pekasih, Ganda. (2017). "Mata yang Menyiksa".http://mediaindonesia.com. Diunduh $8 / 5 / 2018$.

Puboasri, Gali D. Kundharu S. dan Suyitno S.( 2017). "Karakter dalam Preman, Antologi Cerkak Karya Tiwiek S.A. dan Implikasinya terhadap Pembelajaran Bahasa Jawa." Lingua, 14(2), 195-225.

Putri, Dyah P.K. dan Sri Lestari. (2015). "Pembagian Peran dalam Rumah Tangga pada Pasangan Suami Istri Jawa." Surakarta: Universitas Muhammadiyah Surakarta. Journal Penelitian Humaniora, 16(1), 72-85.

Priyatna, Aquarini. (2018). "Feminist Voice in the Works of Indonesian Early Woman" Writers: Reading Novels and Short Stories by Suwarsih Djojopuspito."Journal of International Women's Studies. 19 (2), 230-243.

Quawas, Rula. (2014). "Pinched Lives and Stolen Dreams in Arab Feminist Short Stories".journal of International Women's Studies, 15(1), 54-66.

Rajeswari, V. 2018."Gender Discrimination and Feminist Concern in Shashi Deshpande's A Matter of Time."The Criterion: An International Journal in English, 9(2), 9-15.

Rose, Carol, M. (1990). "Property as Storytelling": Perspectives from Game Theory, Narrative Theory, Feminist Theory. Yale Journal of Law \& the Humanities. 2(37), 3-22.

Santosa, Puji. (2009). "Perlawanan Bangsa Terjajah Atas Harkat dan MartabatBangsa": Telaah Postkolonial Atas Tiga Sajak Indonesia Modern. Atavisme:Jurnal Ilmiah Kajian Sastra, 12(2), 147-156.

Saptawuryandari, Nurweni. (2016). "Perempuan yang Termarginalkan" dalam Cerpen "Menuju Kamar Durhaka" dan "Berita dari Parlemen" Karya Utuy Tatang Sontani. Aksara, 28(1), 39-48.

Sholihah, Rizki Amaliya. (2013). "Problematika Perempuan": Presentasi Kekerasan Gender Pada Cerpen "Lintah" dan "Menyusu Ayah" Karya Djenar Maesa Ayu. Sirok Bastra, 1(1), 109-121.

Sugihastuti, dan Suharto. (2000). "Kritik Sastra Femini”s: Teori dan Aplikasinya.Yogyakarta: Pustaka Pelajar.

Sugihastuti. (2002). “Teori dan Apresiasi Sastra”.Yogyakarta : Pustaka Pelajar

Thakar, Daxa. 2011. "Feminist Perspectives in the Novel Yajnaseni of Pratibha Rai." The Criterion: An International Journal in English, 2(4), 1-8. 
LINGUA, Vol. 15, No. 2, September 2018

p ISSN: 1979 9411; e ISSN: 2442 238X

Http://lingua.pusatbahasa.or.id; Email: presslingua@gmail.com

Center of Language and Culture Studies, Surakarta, Indonesia

Juanda \& Azis. 2018. Penyingkapan Citra Perempuan Cerpen Media Indonesia: Kajian Feminisme.

Lingua (2018), 15(2):71 82. DOI: 10.30957/lingua.v15i2.478.

Vardani, Eka Nova Ali. 2018. "Peranan Nilai-Nilai Karakter Islam dalam Cerpen Aku Ingin Emak Masuk Surga Karya Maidaye Laila Yane.” Jurnal Belajar Bahasa: Jurnal Ilmiah Program Studi Pendidikan Bahasa dan Sastra Indonesia, 3(1),23-37.

Wardani, Ririen dan Yuniar P.A.(2016). "Pemikiran dan Aksi Feminisme Tokoh Perempuan dalam Novel Mataraisa Karya Abidah El-Khaliqy": Journal Indonesian Language Education and Literature, 2(1), 12-21.

Windiyarti, Dara. (2008). "Pemberontakan Perempuan Bali Terhadap Diskriminasi Kelas dan Gender": Kajian Feminis Novel Tarian Bumi Karya Oka Antara. Yogyakarta: Universitas Gajah Mada. Journal Humaniora, 20(3), 286-294.

Yasin, Muhammad Dhimas. 2016. "Kajian Stilistika dalam Teks -Mutawassimin sebagai Bahan Pembelajaran Mata Kuliah Wajib Stilistika." Lingua, 13(2):195-206.

Yin, Kelly. (2017). Post/Feminist Impulses: "Neoliberal Ideology and Class Politics in Annie Wang's The People's Republic of Desire" (2006). Journal of International Women's Studies, 18(3), 66-79.

Youssef, Suwaed Muhammad. (2017). "The Exploitation of Women and Social Change in the Writing of Nawal El-Saadawi." Journal of International Women's Studies, 18(4), 233-246.

Zakarriya, Jihan. (2017). "Sexual Identity and Disturbed Intellectual Female Terrain in J". M. Coetzee's Foe and Jabra Ibrahim Jabra's The Ship: An Ecofeminist Reading."Journal of International Women's Studies, 18(2), 219-232. 